\title{
A study of medical students' experience of the hidden and informal curriculum in obstetrics and gynaecology
}

\section{Dianne Carmody, Alexandra Tregonning and Paul McGurgan}

\section{Corresponding author: Dianne Carmody di.carmody@uwa.edu.au}

Department: School of Women's and Infants' Health, The University of Western Australia, King Edward Memorial Hospital, 374 Bagot Road, Subiaco, Western Australia 6008

Received: 20/03/2015

Accepted: 07/04/2015

Published: 08/04/2015

\begin{abstract}
Objective: To determine student's positive and negative experiences in the hidden and informal curriculum in an obstetrics and gynaecology teaching environment, and to identify students' responses to these experiences.

Study Design: An on-line questionnaire was developed to collect students self-nominated positive and negative experiences and their response to these experiences in the hidden and informal curriculum during their ten-week obstetrics and gynaecology term.

Results: Students' positive and negative experiences were analysed into four main thematic categories: student experience of health professional(s) delivering clinical care; student observation of health professional and other health team members interaction; student experience in clinical care delivery and student experience of teaching and learning with clinical staff. The students' responses to experiences was categorised into themes of student description of response and student noted influence on practice. In addition, the students' response to a negative experience was given allotted a theme student rationalization of experience.

Conclusion: Students described a range of powerful learning experiences in the hidden and informal curriculum of an obstetrics and gynaecology term. Student responses to their experience may help inform planning strategies for increasing student skills in dealing with poor learning encounters in the unplanned curriculum.
\end{abstract}

\footnotetext{
Practice points

- Clinical placements contributed substantial positive and negative student learning experiences from the hidden curriculum

- $\quad$ Students' responses to these experiences depicted a breadth of feelings and impact on their practice

- In this study day-to-day encounters rather than critical events were the principal influential

encounters in the hidden curriculum

- Skill development for students in the formal curriculum may benefit students' dealing with negative encounters in the hidden curriculum

- $\quad$ The learning environment rather than the discipline context was the primary source of students' experiences
}

Keywords: Curriculum. 
Carmody D, Tregonning A and McGurgan P. MedEdPublish 2015, 5: 3

http://dx.doi.org/10.15694/mep.2015.005.0003

Article

\section{Introduction}

The hidden and informal curriculum in medical education is now recognised as a powerful teaching forum. Hafferty described three dimensions of the curriculum: the formal, the informal and the hidden curriculum to outline how students may learn. He defined the formal curriculum as 'the stated, intended, and formally offered and endorsed curriculum'; the informal curriculum as 'an unscripted, predominantly ad hoc, highly interpersonal form of teaching and learning that takes place among and between faculty and students,' and the hidden curriculum as a 'set of influences that function at the level of organizational structure and culture' (Hafferty, 1998). Other authors have used the latter two terms with a slight variation and at times interchangeably. For the purpose of this study the terms hidden and informal curriculum encompasses those teaching and learning experiences outside of the formal curriculum.

Over the last decade research in this area has highlighted the impact of positive and negative student experiences and documented both negative and positive learning experiences in the areas of professionalism (Karnieli-Miller et al., 2010), ethical dilemmas (Hicks, 2001), patient-centeredness role-models (Haidet $e t$ al., 2005) and the conflict between the formal and informal curriculum (Gaufberg et al., 2010, Phillips and Clarke, 2012, White et al., 2009).

Students highly value positive role modeling of respectful relations with patients and colleagues (KarnieliMiller et al., 2011, White et al., 2009) and the benefits of clinical encounters for positive learning opportunities (Gaufberg et al., 2010). A 2008 study (Ozolins et al., 2008) aiming to voice student views of the hidden and informal curriculum stated that students believed these learning opportunities added a depth to their learning and were, at times, essential to achieving core skills. At the other end of the continuum students have reported feelings of powerlessness, confusion and disillusionment at the discord between formal teaching and clinical practice (Gaufberg et al., 2010, White et al., 2009) and the necessity to compete to advance as detrimental to their development. A systematic review of medical students' and residents' decline in empathy attributed the decline to clinical training and the distress caused by parts of the formal, informal and hidden curriculum (Neumann et al., 2011).

However there is less research documenting how students respond to experiences in the hidden / informal curriculum. A study using students' reflective writing to interpret value conflicts in an obstetrics and gynaecology clerkship demonstrated the influence of the hidden curriculum in tolerating and dealing with the values conflicts. Some students stated they addressed the conflict, some said they did nothing and only rarely did they plan to ask for help when dealing with future moral conflicts (Cohn et al., 2009). Another study looking at student responses to teachers' values and behaviours showed reactions to discordant role-modeling that were categorized into challenging, dissociation, silence and confusion. (Phillips and Clarke, 2012).

This study aims to add to the body of knowledge in this field by exploring student-selected positive and negative experiences in the discipline of obstetrics and gynaecology. Although many student experiences in clinical placements are generic, there are some learning experiences that are unique to working in women's health. Furthermore, we wanted to gain insight into the impact of these experiences and how students deal with these encounters in the hidden and informal curriculum.

\section{Methods}

An on-line survey was developed for students undertaking a 10 week term in obstetrics, gynaecology and newborn medicine. The questionnaire was piloted with a focus group of students in the academic year preceding the study. The students participating in the study were in the fifth year of a 6 year undergraduate degree. The medical degree has undergraduate and post graduate students from domestic and international backgrounds. After a comprehensive orientation the students began clinical placements at the end of the first 
week and rotated through a range of clinical areas. This term was their first focused learning experience in women's health. This study was conducted in the last week of each of the four terms for the 2012 academic year.

The survey consisted of twenty statements about the students' experience of the hidden and informal curriculum rated on a modified Likert scale (this part of the study is discussed in a separate paper). The survey also asked the students to give two examples of positive and negative experiences from the hidden or informal curriculum encountered during the obstetrics, gynaecology and newborn medicine term; and to describe their response to the experience or the impact the experience had upon them.

Information about the study, including a definition of the hidden and informal curriculum and an assurance that participation would not impact upon their individual academic outcomes, was given to each student prior to administering the questionnaire. Identifying information was not requested to allow the students to answer openly. Students were free to choose not to participate. Approval to conduct the study was provided by the Ethics Committee of The University of Western Australia.

The qualitative data were reviewed by two of the authors independently, and an inductive thematic analysis of the content was undertaken. The authors listed themes emerging from the data and then met to discuss identified concepts and naming of agreed upon themes. This refining cycle of coding and discussion was repeated multiple times to reach a consensual thematic analysis of the data. At the completion of this process the third author analysed a sample of the data using developed themes to ensure the trustworthiness of the coding process. The minimal number of discrepancies in the independent analysis was agreed upon with discussion.

The students' experiences were themed into categories relating to the nature of the situation they described and were applicable to both positive and negative responses. The students' accounts of their response to the nominated experience encompassed a wider range of content in their descriptions. These data were themed into students' description of their feelings about the experience, the way the event influenced their practice and for the negative encounters a category of student rationalisation of the experience.

The coders aimed to categorise each student experience according to the main content of the description. Many of the students had additional content in their writing; however, in most cases a focal point to their choice of experience was identifiable. In a small number of cases where two core experiences were described the responses were allotted to two different themes.

\section{Results}

Ninety six of the 165 students in the year group participated in the written part of the survey giving a response rate of $58 \%$. Ninety-nine students participated in the initial questionnaire. The demographic data of responders versus non-responders in the Year 5 cohort is shown in Tablel. There were significantly less male responders to the survey compared to non-responders. No other differences were noted in the demographic variables.

There were 255 recorded student experiences, positive and negative, of the hidden and informal curriculum. Students' recorded responses to positive experiences numbered 142 and their responses to negative experiences numbered 109. Students who participated chose to include one or two examples and the subsequent impact response to these examples as shown in Table 2. Any excerpts from the students are reported verbatim.

Students were requested to describe experiences encountered during the term. The location of the experience was not limited to any setting. Interestingly, only 6 students focused on encounters in academic rather than clinical environments. 
Carmody D, Tregonning A and McGurgan P. MedEdPublish 2015, 5: 3

http://dx.doi.org/10.15694/mep.2015.005.0003

The four main themes were students' experience of health professionals delivering clinical care; students' observations of health professionals and other health team member interactions; students' own experience in clinical care delivery; and students' experience of teaching and learning with clinical staff.

The breakdown of the four main themes and their sub-categories of student experiences can be seen in Table 3. The most common themes describe direct involvement of the student in clinical care or with a teaching and learning experience. The highest scoring category for positive (16.9\%) and negative (7.5\%) experiences were in the active teaching and supportive staff in the clinical environment subcategory. Most of these narratives described their experience in general terms encompassing staff overall. Five of the students actually wrote 'they went out of their way to teach.' Typical examples of these experiences are:

Positive: Enthusiastic teachers who were able to give useful feedback about my performance at all my placements.

Negative: Occasionally staff were critical and non-encouraging when it was not justified.

Students also described significant interactions with a health professional, at times in considerable detail. Here are two examples that illustrate this sub-category:

Positive: I was extremely pleased to meet a registrar in EC who found out from the students at the beginning of the shift what we wanted to get out of the shift, covering both academic requirements (cases, summative assessments) and anything we wanted to learn. He found us appropriate cases, and gave good, comprehensive feedback regarding our performance. The feedback was done in a friendly, constructive manner, identifying our weaknesses and giving advice on improvements without putting us down. A wonderful teacher who treated us with respect. He also had a great manner with the patients and the other staff. Some of the doctors and midwives have gone out of their way to provide teaching to medical students in the clinical area.

Negative: Registrar giving me overwhelmingly negative feedback for a case presentation, but not offering any guidance for improvement. Did not introduce herself or find out my name.

Students wrote specifically about their own experience in a clinical setting on the theme of being able to actively participate in care, to be part of the team and actually having an opportunity to practice. The following excerpts demonstrate positive and negative experiences from this sub-category:

Positive: Assisting with multiple surgeries and clinics and feeling like part of the team.

Negative: Being refused entry to a patient's room or being denied the opportunity to physically examine them.

The most notable experiences in the students' experience of health professionals delivering care were the subcategories of demonstration of patient-centred care, observation of team work and demonstration of skills and knowledge. In relation to patient-centred care many students wrote expressively about what they had witnessed. Examples of these descriptions follows:

Positive: Doctor taking a long time to review a patient's situation, despite the clinic being very busy with many other patients waiting. This included educating the patient, carefully examining them, informing other staff that needed to be involved.

Negative: I found the patient manner of one of the Dr's to be quite abrasive, and disregarding of patient's thoughts and answers

No students focused on positive experiences of specific observation of a health professional and other health team member interaction. However, over $8 \%$ of the negative experiences commented on by students were related to poor examples of respect for other professionals or a patient among dialogue with health professionals. Examples are:

I heard various professionals bad mouth other health professionals and some of the patients that were coming into clinic.

Negative comments about patients (not in their presence), for example about weight or alternative beliefs. 
Interestingly, little data specific to the field of obstetrics, gynaecology and newborn medicine emerged in the data analysis. A small number (2.4\%) did express particularly positive experiences in relation to birth and working in this field. Two per cent of students stated they had no negative experiences throughout the term. Many students commented upon a positive learning environment during the term (example below). They were analysed as student experience of teaching and learning rather than the actual discipline content being the focus.

$O \& G$ has provided the best teaching by consultants, senior registrars, registrars, residents and midwives. Staff members are very welcoming and treat us as part of the team. This is one of the few rotations where we actually feel involved and appreciated, rather than 'being in the way and/or wasting time'

\section{Students' responses to positive experiences}

Students' statements about their response to or the impact the experience had upon them were analysed into two main themes; their description of their feelings and identified influence on their practice. Each of these themes has several sub-categories as shown in Table 4 . Almost half $(46 \%)$ of the students described positive feelings ranging from pleased to elated to being in a positive learning environment. A further $13 \%$ were satisfied to have had a positive model.

I felt supported, included and capable. The clinician taught me gently and effectively. The clinician made the patient feel comfortable which is important. I was buzzing with enthusiasm afterwards.

Was greatly rewarding, very thankful that the doctors/midwives are willing to teach and open to students.

I felt very included as part of the team and the knowledge I gained from that encounter has stayed in my head better.

She taught me what it means to be professional and the means of handling a difficult patient.

The students' responses to the influence on their future practice rated most highly in the sub-category of inspiration and motivation. The effusive descriptions demonstrated the students' response:

Better motivation to turn up (on time) for ward rounds, theatre, clinics, tutorials which enhances both learning and teaching. I feel very very very very very keen to learn something new every day!!

Motivated and inspired me to work towards being as good a clinician as this person

It was brilliant, made you feel like a member of the team as opposed to just another face.

Only a small number of students (2\%) documented planning to integrate the skills and knowledge observed in their chosen positive experience.

It was motivating and inspiring to see how clinicians deal with complex and difficult situations in such a professional and positive manner. I was able to pick up strategies to infuse in my clinical practice when interacting with patients.

Thought about how I will go about breaking bad news of all types in the future.

\section{Students' responses to negative experiences}

The students' documented responses to their negative experience or the impact it had upon them were analysed into three main themes as shown in Table 5: a description of their feelings; their noted influence on their practice; and how they rationalised the experience.

Almost one-quarter (24.3\%) of the students rationalised the issue into a seemingly acceptable context to deal with their situation. The excerpts varied in the sophistication of the reasoning of the responses. Below are some examples of students' reasoning in response to their experience:

It made me realise that I have to be more proactive because I may not always get the best teacher who will offer me opportunities to come and learn. While this is hard when you're unfamiliar with a subject or 
environment (eg. at the start of the rotation) it is my responsibility to make this a positive learning experience if no one else will.

I felt hesitant to participate after that, I felt quite guilty and as if I should be very hard on myself and it shook my confidence up a bit....With the next shift, I realised that as medical students, we will make mistakes, and that it's ok to accept the mistake, learn from it and not be so hard on myself since I'd made the mistake despite trying my best.

Didn't fuss me too much - sometimes annoying.

I realise how much easier things would be in the workplace if different professions understood better what the other had to do.

Students' description of influence on their practice formed another theme. An equal number of students (7.2\%) described avoidance behaviour versus dealing with the issue in a professional manner. A very small number $(0.9 \%)$ of students sought other resources to discuss the experience. Short examples of each of these sub-categories are included below:

In short, I left as soon as I was able.

...I of course continued to work with the midwife in a friendly and professional manner.

...I have since discussed this with various senior doctors and have a better idea of what to do if this happens (as either participating party) in the future.

Students expressed a range of feelings as a result of their exposure to a negative experience. Most $(14.4 \%)$ felt they had wasted time and lost motivation, a further $10.8 \%$ described a lack of respect for the health professional involved and nearly $10 \%$ were left concerned or disappointed about the incident. A minimal number $(1.8 \%)$ of students felt they were expected to do something unreasonable. Below are excerpts of students' writings illustrating some of the students' feelings:

Felt in the way, a waste of time.

I simply felt uneasy at the interdisciplinary sniping.

I lost respect for the doctors and midwives involved, which is a shame as they were all good clinicians.

\section{Discussion}

This study reinforces previous acknowledgment of the power of the hidden and informal curriculum in medical education. Discourse sometimes suggests the hidden curriculum is primarily a force in teaching students poor professional behaviours. It is important to recognise the power in both positive and negative learning experiences. The quality of the educational environment may well be a pivotal factor as to how the balance of negative and positive experiences rate for most students.

It was reassuring in this study to note students documented more positive experiences than negative during their obstetrics and gynaecology term. The institution where this study was conducted has received a positive evaluation using the DREEM tool for educational environments (Carmody et al., 2009). It was interesting to note that little importance was attributed to the discipline content of the term, in fact most excerpts could have described an experience in any clinical discipline.

We found a striking feature of the study to be the day-to-day content of the chosen scenarios. The students have picked daily practice rather than critical events to reflect upon. In addition, nearly all of these events are examples from clinical practice. This reaffirms that considerable learning is undertaken in everyday clinical encounters as well as more critical events.

Another striking feature of the study was the very small number of students that sought help from senior professionals or other sources. The scope of this study does not identify reasons for the scarcity in seeking help from other professionals. Possible reasons may be that students have internalised an underlying practice of the need to cope with these issues and therefore do not seek help. Alternatively students may not believe 
suitable opportunities and / or support is available. Lastly students may believe they do not require any extra assistance. It is concerning if any of these possible reasons are true.

It seems students can clearly define negative versus positive learning experiences. None of the authors felt that experiences were inappropriately reported and other studies also seem to suggest that students can decipher good from bad in their learning.

Previous commentaries on the hidden curriculum discussed recognising and shaping it to maximise its potential (Chuang et al., 2010, Gaufberg et al., 2010, Heidi and Clive, 2006). Strategies included effective role modelling, using important events in clinical practice to teach and actively engage learners, making educators consciously aware of the hidden curriculum and ensuring a positive learning environment (Jaye, 2005, Karnieli-Miller et al., 2010).

The students' experiences analysed in this study suggest that all of these strategies would be beneficial in providing positive learning encounters on a day-to-day basis. In fact, it was gratifying and inspiring to read of the students' positive learning encounters and their response to them. The benefits of nurturing the positive interaction potential of the hidden curriculum are clearly apparent.

The hidden curriculum is a dynamic learning forum - continually happening, continually changing and encountered differently by individuals in a range of contexts. In reality it is not hidden at all, however the ad hoc and ongoing nature of the learning experiences for an individual or a small number of people at a time make it extremely difficult to formalise and impossible to plan. The term 'hidden' could suggest this learning has a covert nature when in fact students are expected to learn when they interact in clinical and academic environments.

Perhaps the focus of working with the hidden curriculum in future should be to equip students to deal with their negative encounters. Only some students' descriptions showed the ability to rationalise their experience or to address it in a professional manner. Although not explicitly stated it could be assumed that some students lack the necessary skills to deal with their encounters in a constructive manner. Other work that assessed medical students' ability to deal with conflict of values and engage in reflective practice demonstrated varying levels of ability (Hicks, 2001, Mann et al., 2009). The students' levels of maturity, emotional and social intellect and cultural background are all factors that may influence knowledge and skill in coping.

The ideal for any professional is to be able to use positive and negative experiences to constructively inform future practice. Students may need more knowledge and skills to enable them to complete Kolb's experiential learning cycle $\rightarrow$ experience of concrete experience $\rightarrow$ reflection $\rightarrow$ conceptualisation $\rightarrow$ active experimentation. Their professional world is and will continue to be complex and demanding. Students need building blocks to be able to develop skills in dealing with negative experiences in their professional life. These skills and knowledge need to be developed and refined during student and professional life.

As students are more likely to seek assistance or require additional skills when an event occurs it would be difficult to deliver learning forums for such skills in a timely manner. Forums that are already in use in curriculums are writing reflective pieces on a critical event, reflective journals and groups, and formal mentorship. It may be advantageous to include workshops detailing coping mechanisms and encouraging self-awareness; material and personal resource options; online scenarios and face-to-face stories from health professionals sharing personal experiences when dealing with difficult encounters and the conflict between ideal and actual practice. In an enlightening article on empathy and medical student education Shapiro advocates for the use of positive role-models who 'express vulnerability, share mistakes, incorporate notknowing; who are aware of and transparent about their emotional reactions to patients and about working the edge between intimacy and detachment... ' to influence students' attitudes and learning (Shapiro, 2008).

Future research could look at the effectiveness of some of these tools and the benefits of the students having a strategy toolbox. It may prove useful to have a learning outcome specific to dealing with negative experiences during training so students are aware it is an expected course outcome. Finally, linking some form of 
assessment to the outcome would encourage the students to work at developing skills and knowledge in this area. The ultimate goal would be to put tools in the formal curriculum to aid students when they encounter negative interactions from the hidden curriculum. As Shapiro states these activities should not be on the fringe of medical education but should be treated as 'the heart of medicine'(Shapiro, 2008).

\section{Limitations}

Students who participated in this study were self-selected and therefore the responses may have been biased towards students with a 'story to tell' or those who are concerned by the influence of the hidden curriculum. A student's written response to their experience may not fully reflect the details of their process, their longer term response or the impact of the chosen event. Student responses, both personal and professional, may be extremely complex and influenced by multiple factors. Nevertheless, this study has recorded a range of student experiences and responses that students have declared as important to their learning.

\section{Conclusion}

It is time that the hidden / informal curriculum is given due recognition in the overall planning of teaching and learning. Studies including those described herein have shown that students will encounter positive and negative experiences in the unplanned curriculum, in particular during clinical placements. Their responses to these experiences vary and some may need help in their personal and professional development and coping mechanisms. Introducing and researching innovative teaching forums into the formal curriculum to enable students to maximise their learning from their wider learning environment could be a beneficial step forward.

\section{Declaration of interest}

The authors report no declaration of interest.

\section{Notes on Contributors}

Dianne Carmody designed and implemented the study with her colleagues, analysed the data and was the prime author of the manuscript. She is an Associate Professor and Course Coordinator at the School of Women's and Infants Health, The University of Western Australia.

Alexandra Tregonning designed and implemented the study with her colleagues, analysed the data and contributed to the writing of the manuscript. She is an Associate Professor and Course Coordinator at the School of Women's and Infants Health, The University of Western Australia.

Paul McGurgan designed and implemented the study with his colleagues and was contributed to the writing of the manuscript He is an Associate Professor at the School of Women's and Infants Health, The University of Western Australia. 
Carmody D, Tregonning A and McGurgan P. MedEdPublish 2015, 5: 3

http://dx.doi.org/10.15694/mep.2015.005.0003

\section{References}

Carmody, D., Jacques, A., DENZ-PENHEY, PUDDEY, I. \& NEWNHAM, J. 2009. Perceptions by medical students of their educational environment for obstetrics and gynaecology in metropolitan and rural teaching sites. Medical Teacher, 31, e596-e602.

http://dx.doi.org/10.3109/01421590903193596

Chuang, A. W., Nuthalapaty, F. S., Casey, P. M., Kaczmarczyk, J. M., Cullimore, A. J., Dalrymple, J. L., Dugoff, L., Espey, E. L., Hammoud, M. M., Hueppchen, N. A., Katz, N. T. \& Peskin, E. G. 2010. To the point: reviews in medical education-taking control of the hidden curriculum. American Journal of Obstetrics and Gynecology, 203, 316.e1-316.e6.

http://dx.doi.org/10.1016/i.ajog.2010.04.035

Cohn, F. G., Shapiro, J., Lie, D., Boker, J., Stephens, F. \& Leung, L. A. 2009. Interpreting Values Conflicts Experienced by Obstetrics-Gynecology Clerkship Students Using Reflective Writing. Academic Medicine, $84,587-596$.

http://dx.doi.org/10.1097/ACM.0b013e31819f6ecc

Gaufberg, E., Gaufberg, M., Batalden, R. \& Sands, S. 2010. The Hidden Curriculum: What Can We Learn From Third-Year Medical Student Narrative Reflections? Academic medicine, 85, 1709-1716. http://dx.doi.org/10.1097/ACM.0b013e3181f57899

Hafferty, F. W. 1998. Beyond curriculum reform. Academic medicine, 73, 403-7. http://dx.doi.org/10.1097/00001888-199804000-00013

Haidet, P., Kelly, A., Chou, C. \& THE COMMUNICATION, C., AND CULTURE STUDY GROUP 2005. Characterizing the Patient-Centeredness of Hidden Curricula in Medical Schools: Development and Validation of a New Measure. Academic Medicine, 80, 44-50.

Heidi, L. \& Clive, S. 2006. Medical students' perceptions in relation to ethnicity and gender: a qualitative study. BioMedCentral.

Hicks, L. 2001. Understanding the clinical dilemmas that shape medical students' ethical development: questionnaire survey and focus group study. British Medical Journal, 322, 709.

http://dx.doi.org/10.1136/bmi.322.7288.709

Jaye, C. 2005. Learning to be a Doctor: Medical Educators Talk about the Hidden Curriculum in Medical Education. Focus on health professional education, 7, 1-17.

Karnieli-Miller, O., Vu, R., Frankel, R., Holtman, M., Clyman, S., Hui, S. \& Inui, T. 2011. Which Experiences in the Hidden Curriculum Teach Students About Professionalism? Academic Medicine, 86, 369377. http://dx.doi.org/10.1097/ACM.0b013e3182087d15

Karnieli-Miller, O., Vu, R., Holtman, M., Clyman, S. \& Inui, T. 2010. Medical Students' Professionalism Narratives: A Window on the Informal and Hidden Curriculum. Academic Medicine, 85, 124-133. http://dx.doi.org/10.1097/ACM.0b013e3181c42896

Mann, K., Gordon, J. \& Macleod, A. 2009. Reflection and reflective practice in health professions education: a systematic review. Advances in Health Sciences Education, 14, 595-621. 
Carmody D, Tregonning A and McGurgan P. MedEdPublish 2015, 5: 3

http://dx.doi.org/10.15694/mep.2015.005.0003

http://dx.doi.org/10.1007/s10459-007-9090-2

Neumann, M., Edelhauser, F., Tauschel, D., Fischer, M., Wirtz, M., Woopen, C., Haramati, A. \& Scheffer, C. 2011. Empathy Decline and Its Reasons: A Systematic Review of Studies With Medical Students and Residents. Academic Medicine, 86, 996-1009.

http://dx.doi.org/10.1097/ACM.0b013e318221e615

Ozolins, I., Hall, H. \& Peterson, R. 2008. The Student Voice: Recognising the hidden and informal curriculum in medicine. Medical Teacher, 30, 606-611.

http://dx.doi.org/10.1080/01421590801949933

Phillips, S. P. \& Clarke, M. 2012. More than an education: the hidden curriculum, professional attitudes and career choice. Medical Education, 46, 887-893.

http://dx.doi.org/10.1111/j.1365-2923.2012.04316.x

Shapiro, J. 2008. Philosophy, Ethics, and Humanities in Medicine. Walking a mile in their patients' shoes: empathy and othering in medical students' education. BioMedCentral, 3, 10.

White, C., Kumagai, A., Ross, M. \& Fantone, J. 2009. A Qualitative Exploration of How the Conflict Between the Formal and Informal Curriculum Influences Student Values and Behaviours. Academic Medicine, 84, 597-603.

http://dx.doi.org/10.1097/ACM.0b013e31819fba36 
Carmody D, Tregonning A and McGurgan P. MedEdPublish 2015, 5: 3

http://dx.doi.org/10.15694/mep.2015.005.0003

Table 1:_Demographic data for responders versus non-responders from the $5^{\text {th }}$ year medical student group

\begin{tabular}{|l|l|l|l|}
\hline & $\begin{array}{l}\text { Responders } \\
\mathrm{N}=99(\%)\end{array}$ & $\begin{array}{l}\text { Non-responders } \\
\mathrm{N}=66(\%)\end{array}$ & -value \\
\hline Male & $37(37 \%)$ & $38(58 \%)$ & 0.011 \\
\hline Undergraduate entry & $75(76 \%)$ & $52(79 \%)$ & 0.651 \\
\hline Domestic students & $84(85 \%)$ & $49(74 \%)$ & 0.091 \\
\hline
\end{tabular}

Table 2: Number of Written Responses

\begin{tabular}{|l|l|l|l|l|}
\hline & $\begin{array}{l}\text { Positive } \\
\text { experience }\end{array}$ & $\begin{array}{l}\text { Response to } \\
\text { positive } \\
\text { experience }\end{array}$ & $\begin{array}{l}\text { Negative } \\
\text { experience }\end{array}$ & $\begin{array}{l}\text { Response to } \\
\text { negative } \\
\text { experience }\end{array}$ \\
\hline Example one & 83 & 83 & 70 & 71 \\
\hline Example two & 62 & 62 & 40 & 38 \\
\hline Total & 145 & 142 & 110 & 109 \\
\hline
\end{tabular}

Table 3: Thematic Content of Student Experiences in Hidden and Informal Curriculum

\begin{tabular}{|l|c|c|}
\hline Themes and sub-categories & Positive & Negative \\
\hline Student's experience of health professional(s) delivering clinical care & $8(3.1 \%)$ & $4(1.6 \%)$ \\
\hline Observation of team work & $7(2.7 \%)$ & $7(2.7 \%)$ \\
\hline Demonstration of clinical skills and knowledge & $4(1.6 \%)$ & 0 \\
\hline Demonstration of skills in breaking bad news & $5(2.0 \%)$ & 0 \\
\hline Demonstration of skills in dealing with challenging patient behaviour & $1(0.4 \%)$ & $3(1.2 \%)$ \\
\hline Demonstration of professionalism (respect of patient / ethical approach) & $17(6.7 \%)$ & $8(3.1 \%)$ \\
\hline $\begin{array}{l}\text { Demonstration of patient- centred care (time / thorough explanations/ patient } \\
\text { education) }\end{array}$ & \multicolumn{2}{|c|}{} \\
\hline Student's observation of health professional \& other health team member interaction \\
\hline Respect of other professionals / professional roles & 0 & $11(4.3 \%)$ \\
\hline Demonstration of respect for a patient in dialogue with colleagues & 0 & $11(4.3 \%)$ \\
\hline Student's own experience in clinical care delivery & $7(2.7 \%)$ & $7(2.7 \%)$ \\
\hline Felt welcomed & $24(9.4 \%)$ & $10(3.9 \%)$ \\
\hline Actively participated in / opportunity for clinical care / felt part of team & $6(2.4 \%)$ & \\
\hline Experience of the field of Obstetrics and Gynaecology & $1(0.4 \%)$ & $7(2.7 \%)$ \\
\hline Gender discrimination & 0 & $7(2.7 \%)$ \\
\hline Experienced competition for experience & $\begin{array}{r}\mid \\
\hline \text { Student's experience of teaching and learning with clinical staff }\end{array}$ & $19(7.5 \%)$ \\
\hline Active teaching / supportive staff in learning environment & $20(7.8 \%)$ & $10(3.9 \%)$ \\
\hline Significant interaction with individual health professional & $2(0.8 \%)$ & $1(0.4 \%)$ \\
\hline Effective organisation & 0 & $5(2.0 \%)$ \\
\hline Stated no positive / negative experience & \multicolumn{2}{|c|}{} \\
\hline
\end{tabular}


Table 4: Student response to positive experience

\begin{tabular}{|l|c|}
\hline \multicolumn{2}{|l|}{ Student's description of response to positive experience } \\
\hline $\begin{array}{l}\text { Satisfaction with positive learning environment (words used welcomed / supported/ } \\
\text { involved/ lucky / grateful ) }\end{array}$ & $66(46.5 \%)$ \\
\hline Satisfaction with observing a positive role model(s) & $19(13.4 \%)$ \\
\hline Felt increased confidence / encouraged & $9(6.3 \%)$ \\
\hline Student's noted influence on future practice & $14(9.9 \%)$ \\
\hline Acknowledged learning new knowledge and / or skill & $21(14.8 \%)$ \\
\hline Inspired / motivated to learn / work harder (be good clinician/ pass exams) & $7(4.9 \%)$ \\
\hline Reflected upon own skills and knowledge & $3(2.1 \%)$ \\
\hline Planned to integrate observed new skills and knowledge & $3(2.1 \%)$ \\
\hline Inspired to teach in future &
\end{tabular}

Table 5: Student response to negative experience

\begin{tabular}{|l|c|}
\hline Student's description of response to negative experience & $8(7.3 \%)$ \\
\hline Concerned about poor clinical practice & $12(11.0 \%)$ \\
\hline Loss of respect for health professional(s) involved & $2(1.8 \%)$ \\
\hline Felt expectations of student unreasonable / critical staff & $11(10.1 \%)$ \\
\hline Felt uneasy/ concerned / worried /disappointed about incident & $4(3.7 \%)$ \\
\hline Felt bullied / not respected / angry at incident & $15(13.8)$ \\
\hline Felt less motivated / had wasted time & $4(3.7 \%)$ \\
\hline Felt loss of confidence / affected self-esteem / felt inadequate & \\
\hline Student's rationalisation of the experience & $4(3.7 \%)$ \\
\hline Viewed experience as an opportunity to learn & $1(0.9 \%)$ \\
\hline Increased understanding of issue & $27(24.8 \%)$ \\
\hline Rationalised the issue into a seemingly acceptable context & $1(0.90 \%)$ \\
\hline Student's noted influence on future practice & $3(2.7 \%)$ \\
\hline Learnt what 'not to do' in the future & $8(7.3 \%)$ \\
\hline Aim to make time for students when a clinician & $7(6.5 \%)$ \\
\hline Left the learning experience when able/avoided health professional & $1(0.9 \%)$ \\
\hline Dealt with issue in a professional manner & $1(0.9 \%)$ \\
\hline Sought other resources to discuss experience & \\
\hline Discouraged from career in O \& G &
\end{tabular}

